УДК 533.932, 621.039.623

\title{
PLASMA ELECTRIC POTENTIAL IN THE TJ-II STELLARATOR: NEOCLASSICAL FORMULATION VERSUS MEASUREMENTS
}

\author{
D. Lopez-Bruna ${ }^{1}$, C. Gutierrez-Tapia ${ }^{2}$, J.J. Martinell ${ }^{3}$, A.V. Melnikov ${ }^{4,5}$, L.G. Eliseev ${ }^{4}$, Ph.O. Khabanov ${ }^{4}$, \\ I. Pastor ${ }^{l}$, D. Tafalla ${ }^{1}$
}

\author{
${ }^{1}$ Laboratorio Nacional de Fusion, CIEMAT, Madrid, Spain \\ ${ }^{2}$ Instituto Nacional de Investigaciones Nucleares, Ocoyoacac, Mexico \\ ${ }^{3}$ Instituto de Ciencias Nucleares - Universidad Nacional Autónoma, Mexico, Mexico \\ ${ }^{4}$ National Research Centre «Kurchatov Institute», Moscow, Russia \\ ${ }^{5}$ National Research Nuclear University MEPhI, Moscow, Russia
}

Electric potential measurements by the heavy ion beam probing (HIBP) diagnostic technique, made for a set of ECRH TJ-II discharges, are compared with the results of neoclassical simulations. HIBP-measured electric potential profiles are found to agree qualitatively with theoretical models, that use the standard value of the effective helical ripple. The measured potential values are close to those calculated using the DKES (Drift Kinetic Equation Solver) code. The obtained transport coefficients are very sensitive to the effective helical ripple profile. Fitting the radial profile of the effective helical ripple, one can improve the agreement with the experimental data.

Key words: TJ-II stellarator, neoclassical transport, modelling, electric potential, HIBP diagnostic.

DOI: $10.21517 / 0202-3822-2021-44-1-91-105$

\section{ЭЛЕКТРИЧЕСКИЙ ПОТЕНЦИАЛ ПЛАЗМЫ В СТЕЛЛАРАТОРЕ ТЈ-II: СРАВНЕНИЕ НЕОКЛАССИЧЕСКИХ МОДЕЛЕЙ С ИЗМЕРЕНИЯМИ}

\author{
Д. Лопес-Бруна ${ }^{1}$ ЦЦ. Гутьеррес-Тапиа ${ }^{2}$, Х.Х. Мартинель ${ }^{3}$, А.В. Мельников ${ }^{4,5}$, Л.Г. Елисеев \\ Ф.О. Хабанов ${ }^{4}$ И. Пастор ${ }^{I}$, Д. Тафайя ${ }^{l}$
}

\author{
${ }^{1}$ Национальная лаборатория термоядерного синтеза, СИЕМАТ, Мадрид, Испания \\ ${ }^{2}$ Национальный институт ядерных исследований, Окойоакак, Мексика \\ ${ }^{3}$ Институт ядерных наук - Национальный мексиканский автономный университет, Мехико, Мексика \\ ${ }^{4}$ НИЦ «Курчатовский институт», Москва, Россия \\ ${ }^{5}$ Национальный исследовательский ядерный университет «МИФИ», Москва, Россия
}

Измерения электрического потенциала с помощью зондирования пучком тяжёлых ионов (НІВР) для серии разрядов с ЭЦРнагревом на стеллараторе ТJ-II сравниваются с неоклассическими моделями. Получено качественное согласие между профилями электрического потенциала, измеренными с помощью НІВР, и теоретическими моделями, использующими стандартную величину эффективной винтовой гофрировки. Измеренные значения потенциала также близки к рассчитанным по дрейфовокинетическому коду DKES. Показано, что рассчитанные коэффициенты переноса чувствительны к профилю эффективной винтовой гофрировки. Подбирая радиальный профиль эффективной винтовой гофрировки, можно улучшить согласие с экспериментальными данными.

Ключевые слова: стелларатор ТJ-II, неоклассический перенос, моделирование, электрический потенциал, диагностика НІВР.

\section{INTRODUCTION}

As proven by several scalings, similar power dependencies of transport coefficients and fluxes are found for different current less devices despite their different design criteria. This is a strong indication for similar underlying transport processes. For example, the design of the TJ-II stellarator aimed at the magnetic flexibility in terms of rotational transform and magnetic well but not at transport optimization, while the W7-AS device aimed at reducing neoclassical losses. The two devices are very different in terms of neoclassical transport levels, but the dependencies of electron heat transport on input power are quite similar [1,2]. Thus, neoclassical diffusion seems to explain transport in the core plasma, while a significant anomalous component is found as one approaches the plasma edge. In general, it can be said that transport in stellarator/heliotron devices follows the trends captured in the International Stellarator Scaling ISS04 [3], where it was suggested that the main differences in the transport levels reached by each device were related to the effective helical ripple. This is a measure of how the in homogeneities of the magnetic field modulus on each flux surface affects transport losses in the low collisionality regimes. 
There are many indications that the neoclassical (NC) theory of transport is adequate for current less devices as a component of transport fluxes of particles and heat, but there are not many systematic comparisons. Some attempts to use neoclassical approach for the modeling of the experimental observations [4-6] have shown that in selected plasma regimes neoclassical estimations reasonable concord to the observations [7]. In the TJ-II device, the characterization of plasma potential to date has been based on qualitative comparisons, like low/high density [8] and low/high electron cyclotron resonance heating (ECRH) power [9]. Numerical calculations of the neoclassical transport coefficients have been done with «prototype» profiles paying also attention to low/high density plasmas [10-13]. Some comparison between experiments and neoclassical calculations have been devoted to the formation of electron internal transport barriers (e-ITB) [14] or the so-called "core electron root confinement» (CERC) [15], which in the TJ-II case is too vague a description for the e-ITB phenomenon as will be shown also here. Other calculations and comparisons with the experiments have been included in the inter-machine benchmark [16-18] of neoclassical transport or in specific cases, like a comparison of the thresholds for transport barrier formation in NBI plasmas depending on the presence of magnetic resonances at the edge [19], and the comparisons between experimental particle flux and neoclassical simulations in plasmas perturbed with pellet injection [20]. As a basic general result, it could be said that it «looks like» neoclassical theory plays an important role in the core plasmas of stellarators and the corresponding radial electric fields are «reasonably close» to the experimental values when available. Disagreements in the comparison between theory and experiment, if properly estimated, would be very valuable as indications of physics not accounted for in the derivation of neoclassical formulations. A basic example would be that the departure of the distribution function of some plasma species from being Maxwellian is larger than expected, so the disagreements might depend on the plasma heating methods.

The confrontation of experimental and theoretical transport coefficients is generally difficult, often impossible, partly due to the uncertainties in the particle and heat source profiles. On the other hand, under the assumption that only the neoclassical fluxes are non-intrinsically ambipolar, the radial electric field offers a singular opportunity for the comparison between theory and experiments. The change of root in TJ-II plasmas agrees well with neoclassical expectations based on collisional transport fluxes [21,22] and a reasonable agreement with analytical formulations has been found at the only expense of adjusting the effective helical ripple [23]. This last work has motivated going a step further, trying to refine the results based on more experimental data and adjusting also the transport coefficients that come out of the analytical formulae. If a reasonable degree of predictive capability can be obtained for the demanding TJ-II magnetic configurations, it is very likely that present neoclassical formulations can be adjusted for other devices and become reliable formulae for interpretative transport analyses, where a reasonable estimate of the neoclassical part can help in determining anomalous components. This might be especially useful when there are also measurements that can be related with some form of turbulence. On the other hand, any mismatch between theory and experiment should be the motivation for further research in order to uncover the reasons.

The present paper is a first step on the systematic confrontation between measured plasma electric potential profiles and theoretical estimates. We start this task in mid-density plasmas of the TJ-II heliac, i.e. plasmas with densities around the cut-off $\left(\sim 1.4 \cdot 10^{19} \mathrm{~m}^{-3}\right)$ for the propagation of electron cyclotron waves: measurements of the plasma potential profiles obtained with a heavy-ion-beam probe diagnostic (HIBP) are compared with those obtained from the analytical model [24] used in a previous work [13] for the neoclassical transport coefficients, again taking the effective-ripple profile $\varepsilon_{\text {eff }}$ as the knob to approach the TJ-II geometry; and also with more accurate neoclassical calculations performed with the DKES code [25].

Therefore, there are two levels of benchmarking: among experiment and models and among codes. This last aspect, already started in [13], has been taken a step further in order to exploit the convenience of the semianalytical models based on neoclassical formulations for transport studies.

This paper is organized as follows. In the next Section, we describe the available experimental data for TJII used in this study. Then we explain the neoclassical modeling of the experimental data and compare modeling with experiments. Finally, we discuss the results and give some conclusions.

\section{EXPERIMENTAL DATA}

The experimental data to be compared with neoclassical modeling come from two different experiments with good reproducibility: (i) broad ECRH discharges with continuously varying density and (ii) on-axis ECRH dis- 
charges with two stationary stages. Both experiments have line averaged densities $\bar{n}_{e}>0.4 \cdot 10^{19} \mathrm{~m}^{-3}$ and central electron temperatures $\sim 1 \mathrm{keV}$. The core ion temperatures, around $\sim 0.1 \mathrm{keV}$, vary in these plasmas with a weak proportionality with the average density. The wall conditioning consists of lithiumization on a previously B-coated first wall. The working gas is hydrogen. The magnetic configurations have large volume and rotational transform profiles above the main resonance $1 / 2 \pi=3 / 2$, with the typical low magnetic shear of TJ-II vacuum configurations.

Discharges with broad ECRH. The discharges belong to an experiment on HIBP measurements where the plasma-facing mirrors of two gyrotrons delivering nominally $220 \mathrm{~kW}$ each, aim towards $\rho_{\mathrm{ECH}} \gtrsim 0.6$. The heating deposition profile is expected to be very broad due to poor first pass absorption. The broad heat deposition has two main advantages for our purposes: (i) it eases approaching the density cut-off value for ECRH without $\bar{n}_{e}$ loosing control of the density evolution, and (ii) pump-out losses that might be significant in well-focused on-axis ECRH discharges are expected to be reduced. This second advantage should avoid that escaping highperpendicular-velocity electrons contribute to the radial electric field, and consequently the neoclassical calculations based only on the ambipolarity condition for the collisional fluxes are more meaningful.

The plasmas were confined in two similar magnetic configurations, labeled 100_44_64 and 100_46_65 in the nomenclature of the TJ-II field-coils settings, which are equivalent in terms of effective helical ripple and neoclassical mono-energetic transport coefficients [12].

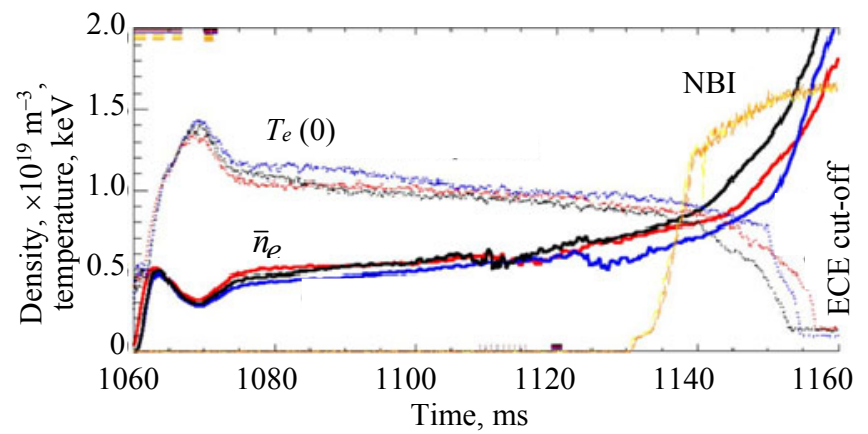

Fig. 1. Time traces of electron density $\left(n_{e}\right)$ and approximate electron temperature $\left(T_{e}\right)$ based on the central electron cyclotron emission (dashes) for three discharges (one color each) of experiments with broad ECRH

Different densities were obtained through pre-

programmed gas puffing waveforms. Electron density and electron temperature profiles were obtained with the Thomson Scattering (TS) diagnostic and the line averaged densities were obtained from interferometry using two different methods to count the fringes with very similar results. Fig. 1 shows the time traces of line-averaged electron density and an approximate central electron temperature (the ECE diagnostic was not absolutely calibrated) for three discharges of the set, where the density increases during the final part due to the start of co-injected NBI. Data considered in this work correspond mostly to line-density values up to the ECE cut-off, conditions in which the NBI heat deposition is either zero or small $(<50 \mathrm{~kW})$ with respect to the ECRH. The highest densities are often reached quite rapidly, with values of the characteristic time $\left[\left(1 / \bar{n}_{e}\right) d \bar{n}_{e} / d t\right]^{-1} \sim 20 \mathrm{~ms}$, which is close to the slowest scanning HIBP time per profile (10 ms). Therefore, HIBP profiles corresponding to the highest densities are less reliable and more variability than at lower densities $\left(\bar{n} \lessgtr 0.9 \cdot 10^{19} \mathrm{~m}^{-3}\right)$ is expected.

The density and electron temperature profiles were built based on a Bayesian approach [26] that allows for the combination of several diagnostics. Unfortunately, the ion temperature and edge values could not be obtained in this set of discharges. We have used another set of previous discharges also heated by ECRH with $\rho_{\mathrm{ECH}} \gtrsim 0.6$ and similar densities (table). This set has been used to obtain the edge density and electron temperature, $n_{e a}$ and $T_{e a}$ respectively, and the core ion temperature, $T_{i 0}$. The electron density and temperatures from the TS system are reliable up to $\rho \sim 0.7$ in these discharges due to the small densities in the outer plasma region. Helium-beam data have been used to have a better determination of the edge values.

Discharges from the 24-Nov-2016 experiment $\left(N_{\|}=0\right.$, $\rho$ ECH $=0.64$, configuration 100_44_64, $\left.P_{\mathrm{ECH}}=240+240 \mathrm{~kW}\right)$. Line densities $\left(\bar{n}_{e}\right)$ and central ion temperatures $\left(T_{i 0}\right)$ are time averages during, respectively, 2 and $5 \mathrm{~ms}$ (see Fig. 2)

\begin{tabular}{c|c|c|c|c|c}
\hline Discharge & Time, $\mathrm{ms}$ & $\bar{n}_{e} 10^{19} \mathrm{~m}^{-3}$ & $T_{i 0}, \mathrm{eV}$ & $n_{e a}, 10^{19} \mathrm{~m}^{-3}$ & $T_{\text {ea }}, \mathrm{eV}$ \\
\hline 42767 & 1118.5 & 1.11 & - & $0.12 \pm 0.06$ & $22 \pm 8$ \\
42772 & 1131.5 & 0.62 & 110 & $0.10 \pm 0.04$ & $45 \pm 11$ \\
42772 & 1157.0 & 1.30 & 143 & $0.25 \pm 0.20$ & $10 \pm 5$ \\
42775 & 1131.5 & 1.00 & 130 & $0.09 \pm 0.05$ & $38 \pm 11$ \\
42784 & 1111.5 & 0.59 & 110 & $0.09 \pm 0.04$ & $54 \pm 11$ \\
42784 & 1133.0 & 0.83 & 116 & $0.09 \pm 0.04$ & $51 \pm 13$ \\
\hline
\end{tabular}


Since the bulk ion temperature in ECRH TJ-II plasmas increases with line density at fixed power, we have adjusted $T_{i 0}$ (Fig. 2) in order to obtain a fit that will be used to obtain the ion temperature for any of the densities in the experiment with broad ECRH. Based on the experience that the ion temperature profile $T_{i}(\rho)$ is similar to the density one, $n_{e}(\rho)$, when ECRH dominates [27], we have chosen a formula that is based on $n_{e}$ but permits fixing the edge ion temperature to a fraction of the electron edge temperature, here set to $70 \%$,

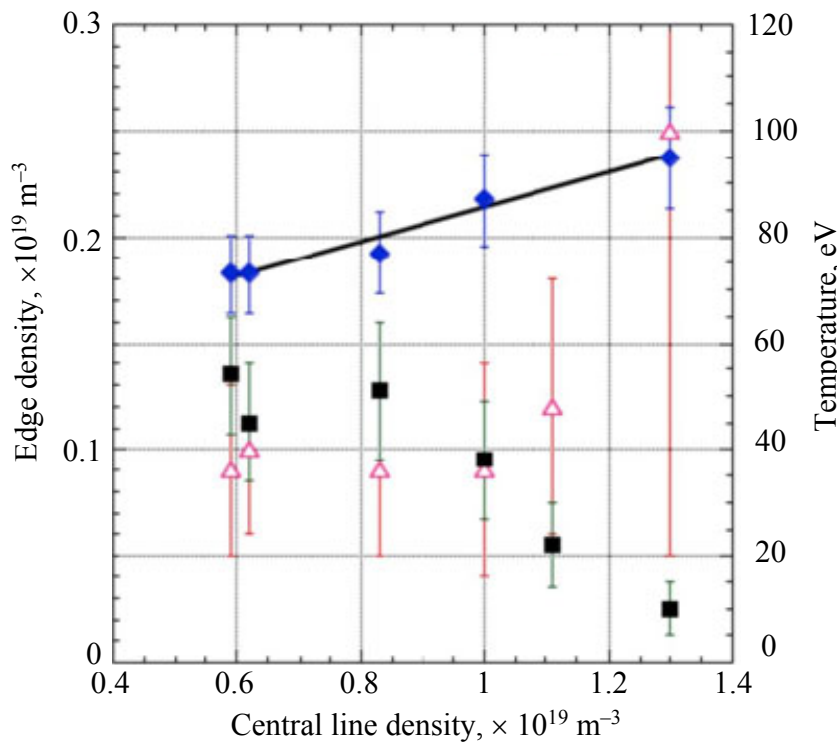

Fig. 2. Representation of the data in table 1 . The error in $T_{i 0}$ is taken as $\pm 10 \%: \triangle-n_{e}(a) ; \diamond-T_{i}(0) ; \quad-T_{e}(a)$ $y=52.763+32.532 x, R=0.98439$

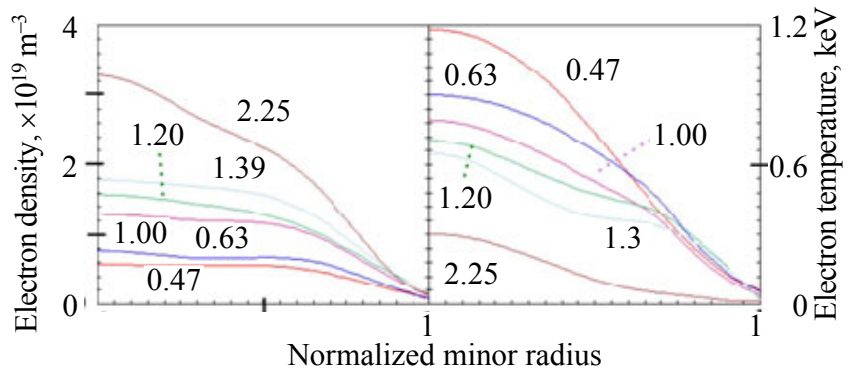

Fig. 3. Electron density and electron temperature profiles at different line averaged densities (labeled in $10^{19} \mathrm{~m}^{-3}$ units) taken at TS time from the set of discharges TJ-II № $46964-46979$

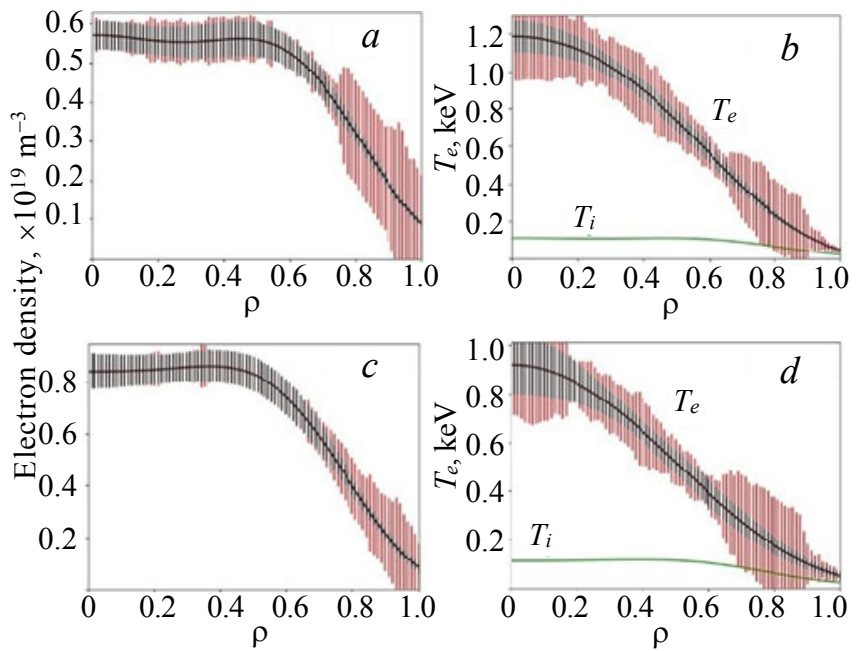

Fig. 4. Density $(a, c)$ and temperature profiles for the two stages $(a, b-1$ st, $c, d-2$ nd stage). Error bars refer to: (red) the estimate from the Bayesian method, where the high uncertainties are due to the lack of Thomson Scattering data in the outer plasma region; and (black) the standard deviation from repetitions of discharges

$$
T_{i}(\rho)=\frac{0.053+0.0325 \bar{n}_{e}}{n_{e 0}}\left[n_{e}(\rho)-\rho^{a} n_{e a}\right]+0.7 \rho^{b} T_{e a},
$$

where $a$ and $b(\sim 1)$ are powers that serve occasionally to make $T_{i}<T_{e}$ near the edge. Observe also that the core value follows the fit in Fig. 2. The near-edge ion temperatures are thus compatible with the values found in $[28,29]$, but the profiles $T_{i}(\rho)$ are still not well determined and this is acknowledged as the main uncertainty in these experiments. Consequently, this is also a source of uncertainty in modeling the ambipolar electric potential.

Two variants of the input data will be used in Section «MODELING». Contour maps of the plasma potential calculated by the models will be compared with analogous maps from experimentally obtained plasma potential profiles. The calculations will be based either on profiles coming from individual discharges of different densities, or from averages. In the first case, and since there is only one bring of the TS laser per discharge, the electron density and electron temperature profiles are taken at different densities from similarly evolving discharges (see Fig. 1). Fig. 3 shows some of the profiles thus obtained (see Fig. 4 for uncertainties in the profiles, and also Fig. 2 in [13]). In the case of profiles coming from averages we group the discharges according to similar values of the line density at the relevant time so as to obtain representative TS profiles $n_{e}(\rho)$ and $T_{e}(\rho)$, and the corresponding neoclassical transport coefficients and electric fields from DKES. Using $10^{19} \mathrm{~m}^{-3}$ as density unit, we have the following groups of «density (discharges)»:

— configuration 100_44_64: 1.4 (46 979), 1.2 (46 966, 46 976-46 978), 1.0 (46 967-46 968), 0.8 (46 969-46 971) and 0.6 (46 972—46 975);

— configuration 100_46_65: $1.4 \quad$ (46 99246 993), 0.9 (46 994-46 995), 0.7 (46 996-46 997) and 0.6 (46 998-47 000).

All the previous discharges have HIBP data in scanning mode, i.e., plasma profiles are available for all the near-stationary phases of the plasma. Since the scanning times from low to high-held side range from 10 to $20 \mathrm{~ms}$, each profile is obtained during half these times. Therefore, the scanning can be taken as corresponding to steady plasma, if the evolution is slow 
enough. In the worst case (10 ms per profile) and taking the line density as proxy for the plasma evolution, we can set a limit at $\bar{n}_{e} /\left(d \bar{n}_{e} / d t\right)<20 \mathrm{~ms}$.

Two-stage on-axis ECRH discharges. Another experimental set has been obtained from repetitions of two-stage discharges under on-axis ECRH only. In this case, the plasmas can be considered perfectly stationary for practical purposes. During a first stage, two ECRH lines are active delivering $220+240 \mathrm{~kW}$ and the gaspuffing waveform is set so as to keep the line averaged density constant for nearly $100 \mathrm{~ms}$. Then the $240 \mathrm{~kW}$ gyrotron for ECRH is turned off, and the gas puff is changed in order to have an approximately constant but higher density during a second stage. Therefore, the two stages can be characterized by different collisionalities:

- 1st stage: lower collisionality, $\bar{n}_{e} \approx 0.45 \cdot 10^{19} \mathrm{~m}^{-3} ; T_{e}(0) \approx 1.2 \mathrm{keV}$;

- 2nd stage: higher collisionality, $\bar{n}_{e} \approx 0.75 \cdot 10^{19} \mathrm{~m}^{-3} ; T_{e}(0) \approx 0.9 \mathrm{keV}$.

The choices of densities and temperatures respond to the experience that, in the lower collisionality regime (1st stage), the radial electric field remains in the neoclassical electron root $\left(E_{r}>0\right)$ regime in all of the plasma volume; while in the higher collisionality regime (2nd stage) part of the plasma in the outer zone is in the ion root $\left(E_{r}<0\right)$.

Plasma profiles shown in Fig. 4 charge-exchange have been built for each one of the two stages of this set of discharges. Owing to repeatability, TS-profiles have been combined with interferometry and He-beam data for groups of discharges with line densities in the ranges $0.49 \pm 0.03$ (1st stage, 15 discharges) and $0.71 \pm 0.05$ (2nd stage, 13 discharges), always in units of $10^{19} \mathrm{~m}^{-3}$. As in the previous experiment, the profiles have been adjusted with Bessel functions of 4th order (electron density) and 3rd order (electron temperature); but the ion temperature is not well determined. Measured core values are found around $0.09 \pm 0.01 \mathrm{keV}$ although the neutrals energy spectrum obtained by the charge-exchange (CX) diagnostic can hardly be explained with just one slope (one thermal velocity). Therefore, the experimental profiles have been defined again using Eq. 1, but exchanging the fitting value by $T_{i}(0)$ values compatible with the measured core temperatures.

Since in the two experimental sets $T_{i}(\rho)$ is poorly determined, the comparison with HIBP measurements of the plasma electric potential will be done also based on a self-consistent ion temperature profile as explained in Section «MODELING».

HIBP measurements. In what follows we use two sets of HIBP data. The diagnostics worked in scanning mode during the discharges with broad ECRH (see subsection «Discharges...») using periods of about 5 ms per profile (10 ms going from the extreme low to high field sides) and $7 \mathrm{~ms}$ per profile in some cases [30]. In the twostage discharges (subsection «Two-stage...»), where plasmas were very steady, a larger scanning period was taken ( $\approx 15 \mathrm{~ms}$ per profile) in order to allow for local measurements of fluctuations with the purpose of elaborating a twodimensional map of electrostatic data [31]. Here we are only interested on the data taken by the diagnostics following a scanning line that passes close to the magnetic axis in order to obtain the plasma electric potential $\varphi(\rho)$.

\section{MODELING}

Experimental density and temperature profiles are taken as input to obtain the radial electric field according to the formulation given in $[24,32]$. Here we briefly remind that the authors provided expressions for the monoenergetic particle fluxes in the three typical low-collisionality regimes of stellarators, $D_{1 / v} \propto 1 / v, D_{\sqrt{v}} \propto \sqrt{v / E_{r}^{3}}$

and $D_{v} \propto v / E_{r}^{2}$. We obtain numerically the convolution of these coefficients with the Maxwellian distributions associated with the input temperature profiles. The results converge if the convolution integrals extend to three or more thermal speeds [22]. Once the transport coefficients are obtained for the thermal species as functions of the radial electric field, the ambipolarity condition of null radial current is solved by equating the collisional radial fluxes of electrons and ions, $\Gamma_{e}\left(E_{r}\right)=\Gamma_{i}\left(E_{r}\right)$, and the radial electric field is obtained. This, in turn, is integrated radially to obtain the electric plasma potential in order to compare the results with the experimental profiles. The radial electric field and plasma potential are related through the flux-surface averaged gradient of the vacuum flux-surface radial coordinate, $E_{r}(\rho)=-\nabla \varphi(\rho)=-\partial_{\rho} \varphi\langle|\nabla \rho|\rangle(\rho)$.

As mentioned in the Introduction, we consider the neoclassical formulations as correct except for an undetermined effective ripple, $\varepsilon_{\text {eff }}(\rho)$, which will be adjusted in order to reproduce the experimental results. It must 
be reminded that there is flexibility in the choice of $\varepsilon_{\text {eff }}$ because the radial electric field is rather robust in this respect, while the changes in ripple have a stronger impact in the resulting transport coefficients.

Finally, as part of the study we have let the neoclassical modeling replace the uncertainties in the ion temperature profiles. Therefore, in the results that follow we show the calculated plasma potentials based on (i) all the experimental profiles or (ii) only the well-characterized electron density and electron temperature profiles with an evolving ion temperature profile given by the neoclassical model itself. How $T_{i}(\rho)$ is determined in case (ii) is explained next.

Transport calculations for TJ-II are commonly done using the ASTRA suite [33] where the geometry is represented by diagonal, flux-surface averaged metric coefficients like $\langle|\nabla \rho|\rangle(\rho)$. The calculations of the ambipolar electric field and corresponding neoclassical transport coefficients according to different models have been included in ASTRA [22]. The experimental density and temperature profiles are inputs for the evaluation of $E_{r}$, but in some cases we have substituted the ion temperature by its evolving profile under the following considerations. The ion heat fluxes are due to a neoclassical thermal diffusivity, $\chi_{i}^{\mathrm{NC}}$, plus an anomalous contribution. To make things simpler, the latter is not based on a physical model but on a simple function that gives additional heat fluxes near the edge. Therefore, we set an ion heat transport coefficient

$$
\chi=\chi_{i}^{\mathrm{NC}}+2 \rho^{4}
$$

and a corresponding ion heat flux $\propto \chi_{i} n \partial_{\rho} T_{i}$. Since there is no direct ion heating mechanism in the present discharges, we set Coulomb collisions with the electrons and charge-exchange losses as the only ion heat sources,

$$
P_{i}=P_{e a}-P_{i}^{\mathrm{CX}} \text {. }
$$

The term $P_{i}^{\mathrm{CX}}$ requires profiles of neutral density and temperature. Since this term is not dominant and, for our present purposes, we just need a reasonable ion energy sink, we have obtained such profiles from a calculation with EIRENE [34] assuming a typical particle confinement time of these discharges [2, 35]. Typical net CX power losses are at most a few $\mathrm{kW}$ in these plasmas, much smaller than electron-ion heat exchange. It will be seen, however, that predicted core ion temperatures are considerably higher than those obtained with the CX neutral particle analyzer.

As a comparison point, other neoclassical computations have been done using the kinetic equation through DKES code. In the integration of the monoenergetic diffusion coefficients over Maxwellian distributions the experimental profiles are used, but due to the uncertainties in $T_{i}(\rho)$, this profile was varied by a constant factor in order to achieve the convergence of the integrals in some cases. The well-known problem with DKES is the difficulty in converging at low collisionalities and thus this is an important source of inaccuracy in our results using this approach. Just as in the Astra computations, the radial electric field is obtained from the ambipolarity condition and the right root is determined by minimization o the heat production rate [17].

\section{COMPARISON BETWEEN MODELS AND EXPERIMENTS}

Experimental results. Fig. 5 shows contours of the measured plasma potential as a function of averaged line-density and normalized minor radius for three TJ-II discharges: № 46969 (HIBP scanning at $7.5 \mathrm{~ms} /$ profile), № 46996 (10 ms/profile) and № 47000 (5 ms/profile). All of them correspond to the experiments with broad ECRH deposition and their density and temperature profiles are similar to those of Fig. 1.
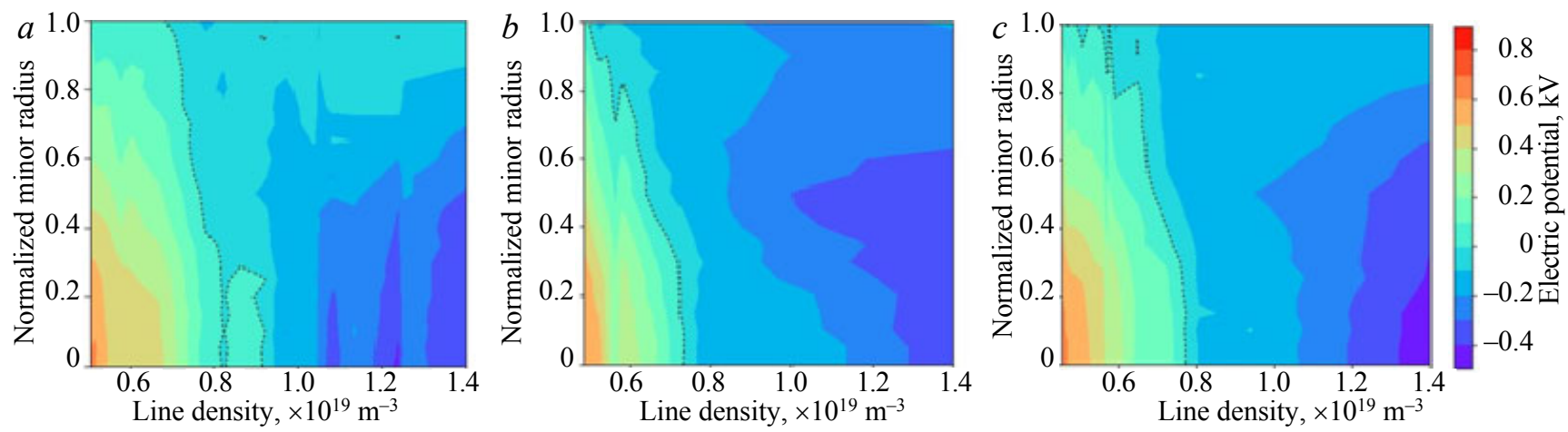

Fig. 5. Contours $\varphi\left(\bar{n}_{e}, \rho\right)$ of the experimental plasma electric potential profiles as a function of the line-averaged density in three TJ-II discharges ( $a$ - № 46 969, $b$ - № 46 996, $c$ — № 47 000) with broad ECRH. Thin dashed lines mark $\varphi=0$ 
The variation of plasma potential with density is quite similar among discharges for $\bar{n}_{e} \lesssim 0.9 \cdot 10^{19} \mathrm{~m}^{-3}$. Core values $\varphi(0) \approx 0.8 \mathrm{kV}$ are found at the smallest densities when the plasma potential is everywhere positive. Negative values start to appear with small increments of the density and the plasma central potential decays to null voltages around $\bar{n}_{e}=0.8 \cdot 10^{19} \mathrm{~m}^{-3}$.

The variability is larger for higher densities. This could be due to the poorer stationarity mentioned in Subsection «Discharges...». Still, we can see that the voltages are very small at $0.8 \lesssim \bar{n}_{e} \lesssim 0.9\left(\times 10^{19} \mathrm{~m}^{-3}\right)$ and negative voltages of a few hundred volts are reached in the core region when the density is further increased.

Plasma potential profiles obtained in one of the repetitions of the two- stage discharges are plotted in Fig. 6. The near-edge values from HIBP are found to be in agreement with the values obtained using a Langmuir probe, although the uncertainty of the HIBP profiles is larger in this plasma region. According to the measurements, there is no essential difference with the profiles obtained with broad ECRH: in the two-stage discharges we find $\varphi(0) \approx 0.8 \mathrm{kV}$ at $n_{e}(0)$ $\approx 0.6 \cdot 10^{19} \mathrm{~m}^{-3}$, similar to Fig. 5 where this central density value corresponds to average density $\approx 0.5 \cdot 10^{19} \mathrm{~m}^{-3}$. Actually, core temperatures are quite similar: $T_{e}(0) \approx 1.2 \mathrm{keV}$ in both types of experiments (see Figs. 3, 4).

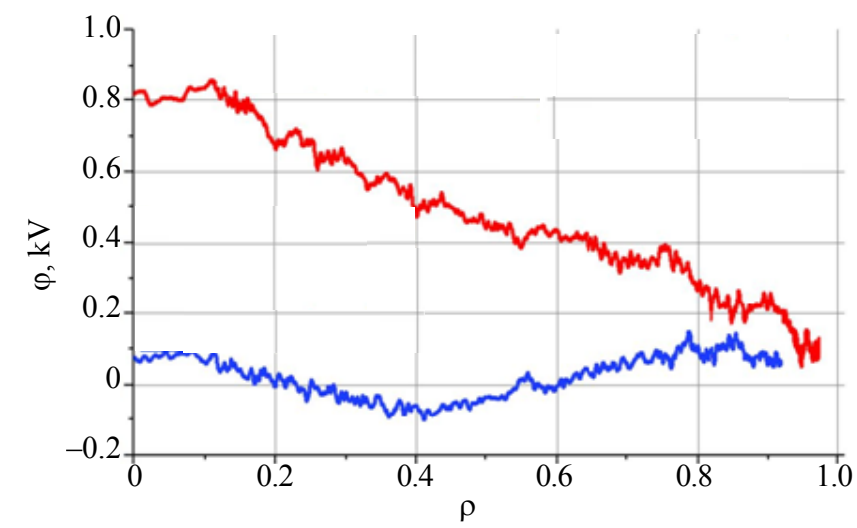

Fig. 6. HIBP profiles of the plasma electrostatic potential $\varphi(\rho)$ in each of the two stages of TJ-II discharges with on-axis ECRH: 1 st stage, $T_{\mathrm{e} 0} \approx 1.2, T_{\mathrm{i} 0} \approx 0.08 \mathrm{keV}, n_{\mathrm{e} 0} \approx 0.6 \cdot 10^{19} \mathrm{~m}^{-3}(\mathrm{red}) ;$ 2nd stage, $T_{\mathrm{e} 0} \approx 0.9, T_{\mathrm{i} 0} \approx 0.09 \mathrm{keV}, n_{\mathrm{e} 0} \approx 0.8 \cdot 10^{19} \mathrm{~m}^{-3}$ (blue)

Neoclassical calculations. The calculations to be compared with the experimental data of the previous sub-section have been performed in two different ways. The analytical formulation [24] has been used to reproduce either (i) the experimental profiles or (ii) DKES results. In both cases we have used the effective ripple, $\varepsilon_{\text {eff }}(\rho)$, to modify the calculations. In case (i) we have simply searched for one effective ripple that allows us to approximate the experimental plasma potential profiles in all the data at once. In case (ii), we have imposed $\varepsilon_{\text {eff }}$ profiles like those found in the literature for the TJ-II stellarator, which, as we shall see later, give $E_{r}$ and diffusivity values on the order of those obtained numerically with DKES.

We begin by showing the results of the neoclassical formulation on different sets of data when $\varepsilon_{\text {eff }}$ is adjusted in order to approximately match HIBP values. The four boxes in Fig. 7 illustrate the results in several variants of the calculations with an effective ripple of the form

$$
\varepsilon_{\text {eff }}=0.003 \cdot 10^{1.2 \rho^{0.6}}
$$

which is around ten times smaller than the ripple found numerically in the literature for TJ-II configurations $[12,17,36]$. The evaluation of $\varphi(\rho)$ is based on the integral of $E_{r}$ from the plasma edge, where there is an unknown value $\varphi_{a}=\varphi(\rho=1)$ not accounted for in the models. In order to make a comparison with experimental values we present the results of the calculated $\varphi(\rho)$ with an offset $\varphi_{a}$ taken from the experimental data near the edge, $\varphi_{a}^{\mathrm{HIBP}}$. In the top panels (see Figs. 7, $a, b$ ) we show the calculations based on averaged experimental profiles. The densities start at $\bar{n}_{e}=0.6 \cdot 10^{19}$ $\mathrm{m}^{-3}$ because this is the smallest one in the set of averages. In the first case (see Fig. 7, $a$ ), the experimental profiles have been used as explained in Subsection «Discharges...». Low-density poten-
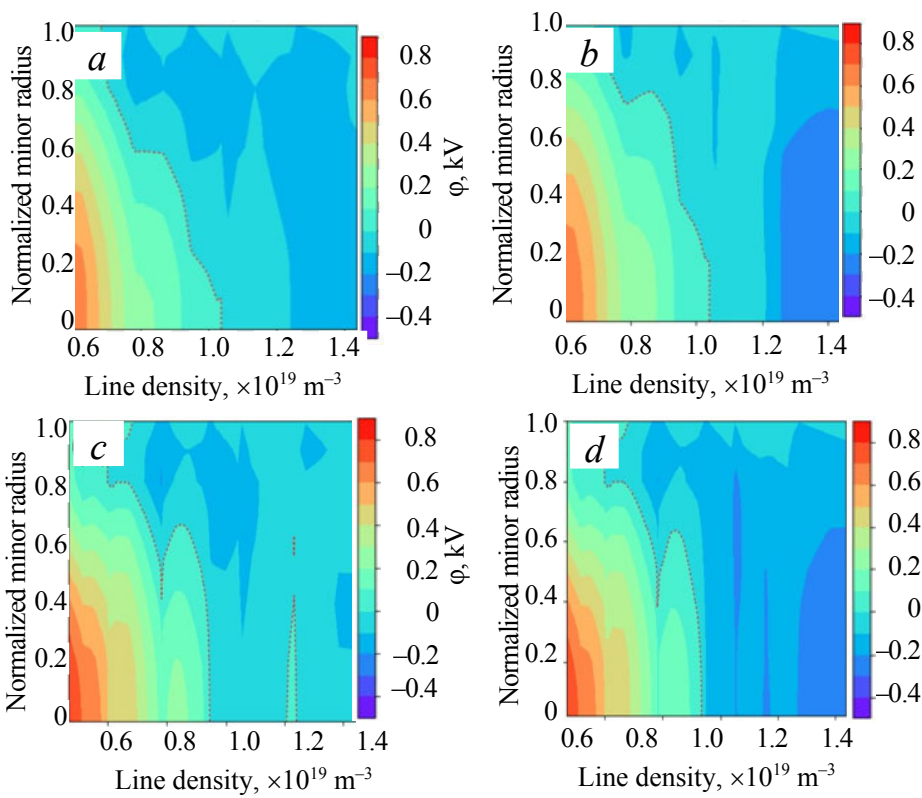

Fig. 7. Contours of the calculated plasma electric potential profiles in TJ-II discharges with broad ECRH using $\varphi\left(\bar{n}_{e}, \rho\right)$ small ripple Eq. 4: $(a)$ averaged experimental profiles in groups of similar density; $(b)$ the same except that $T_{i}(\rho)$ is obtained from ion energy balance; $(c)$ individual experimental profiles from different discharges; $(d)$ the same except $T_{i}(\rho)$ from ion energy balance. A thin dashed line marks $\varphi=0$ 
tials are in fairly good agreement with the measurements shown in Fig. 5, but high density values seem underestimated in magnitude. When the ion temperature is allowed to evolve using the diffusivity and heat sources of Eqs. 2 and 3 we obtain higher ion temperatures during the stage of higher densities and correspondingly lower core plasma potentials (see Fig. 7, $b$ ). The results from the neoclassical formulation are still acceptably similar to the measurements when profiles from single discharges at different densities are used instead of averages (bottom panels). The core values $\varphi(0) \sim 0.7 \mathrm{kV}$ at the smallest density are somewhat larger than the experimental ones, $\varphi(0)^{\mathrm{HIBP}} \sim 0.6 \mathrm{kV}$. Negative values also start to appear with small increments of the density but now the plasma center decays to null voltages at lower values of around $\bar{n}_{e}=0.9 \cdot 10^{19} \mathrm{~m}^{-3}$. As in the case with averaged density and temperature profiles in panels (see Figs. 7, $a, b$ ), the experimental $T_{i}$ gives smaller magnitude of the negative plasma potential at the highest densities (see Fig. 7,c) than the evolving $T_{i}$ case (see Fig. 7, d), but even this latter case yields core plasma potentials $\sim-0.25 \mathrm{kV}$ that are smaller in magnitude than the experimental values, $\sim-0.40 \mathrm{kV}$.

The magnitude we are normally interested in is not the plasma potential, but the radial electric field. Radial derivatives amplify the uncertainties, which is the reason why we have made a comparison with the plasma potential so far. Despite this, we make the comparison of radial electric field profiles in what follows.

In the two-stage discharges where we can use averages of the profiles for the modeling of $E_{r}$, potential profiles $\varphi(\rho)$ can be obtained with small errors, while the experimental $\varphi^{\mathrm{HIBP}}$ is quite accurate thus a fairly reliable
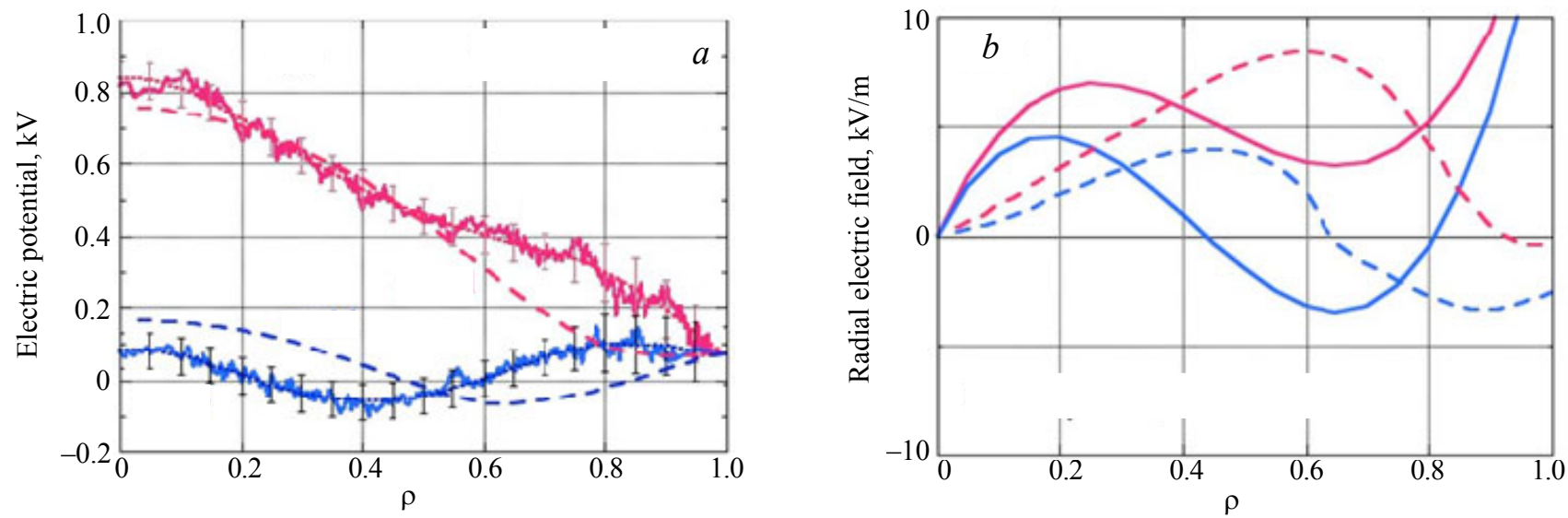

Fig. 8. Plasma potential profiles in the two-stage experiments (series \#484-xy): lower collisionality (460 kW ECRH and line density $0.45 \cdot 10^{19} \mathrm{~m}^{-3}$, magenta) and higher collisionality $\left(220 \mathrm{~kW}\right.$ and $0.75 \cdot 10^{19} \mathrm{~m}^{-3}$, blue). Solid lines are HIBP data and dotted lines are corresponding polynomial fits. Model calculations with the small ripple (Eq. 4) are shown by dashed lines (a). Radial electric field from the derivative of the fitted polynomials (-) and from modeling $(---)(b)$
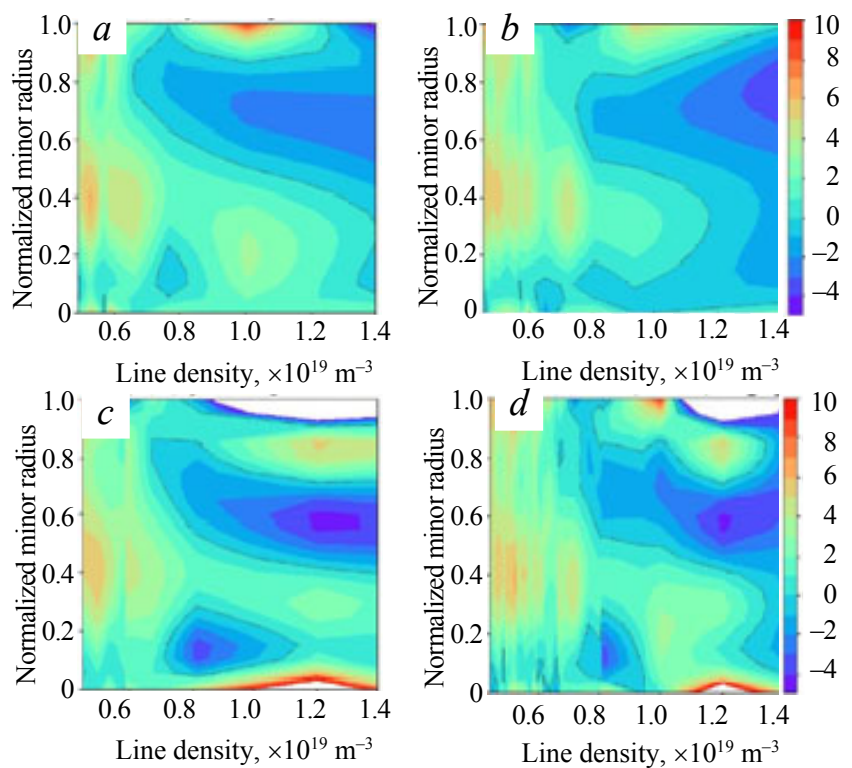

Fig. 9. Contour plots of the radial electric field, obtained from derivation of the spline-fits to HIBP plasma potential profiles, in the indicated discharges: № 46996 (a), № 47000 (b), № 46992 (c), configuration 100_44_64 $(d)$
$E_{r}(\rho)$ can be derived. Fig. 8 shows the comparison between experimental values and neoclassical model values using the same ripple as for the broad ECRH experiments. Fig. $8, a$ shows the plasma potential profiles and Fig. $8, b$ the corresponding radial electric fields. As expected, the differences in $E_{r}(\rho)$ are large despite the similar magnitudes of the bulk plasma potential. The large $E_{r}$ from HIBP near the edge is an artifact of the fitting to polynomials; by inspection of Fig. 8, $a$, the near-edge HIBP electric field during the 2nd stage could be close to zero rather than growing.

Fig. 9 shows the contour plots obtained after obtaining the derivative of the HIBP plasma potential profiles measured during several discharges (see plot titles) of the broad-ECRH experiments, including also an ensemble of profiles from different discharges in the magnetic configuration 100_44_64 (bottom right plot). The $\varphi^{\mathrm{HIBP}}(\rho)$ profiles have been fit using a cubic spline, from which we have obtained the electric field as 


$$
E_{r}^{\mathrm{HIBP}} \equiv-\frac{1.2}{a} \frac{d \varphi^{\mathrm{HIBP}}}{d \rho},
$$

where the factor 1.2 is a good figure for the flux-surface average of $|\nabla \rho|$ in most of the plasma, and $a=0.19 \mathrm{~m}$ is the minor radius that corresponds to these magnetic configurations. This is a simplification that works very well for the present practical purposes. The figure aims at showing explicitly the variability of the multi-profile measurements, as well as to allow for a visual comparison with the calculated $E_{r}$. We present the whole range $0 \lesssim \rho \lesssim 1$ even though the values near the boundaries are affected, as before, by the polynomial fits. However, the latter are very good in the range, say, $0.1 \lesssim \rho \lesssim 0.9$, where we find consistency in the data from the different panels in Fig. 9:

$-E_{r}>0$ (electron root) for line densities below, approximately, $0.7 \cdot 10^{19} \mathrm{~m}^{-3}$. The highest $E_{r}$ values are found around $\rho=0.4$;

— the ion root seems to appear inside the plasma, around $0.7 \leqslant \rho \lessgtr 0.8$, in agreement with Doppler reflectometry [37];

- the plasma region with positive electric field moves towards the core as the density increases;

- the plasma goes through a stage of near null radial electric field in most of the plasma at line-densities around $\bar{n}_{e} \sim 0.8 \cdot 10^{19} \mathrm{~m}^{-3}$;

- only at the highest densities does the plasma stay completely in the ion root, $\bar{n}_{e}>1.2 \cdot 10^{19} \mathrm{~m}^{-3}$.

As expected after the results obtained for the two-stage discharges, these features are hardly obtained with the modeling based on the small ripple (Eq. 4), which we do not show for brevity: the electron root is found in the whole plasma (except at the very edge) for the lowest densities, but the maximum $E_{r}$ is found around $0.6 \lesssim \rho \lessgtr 0.8$ and the ion root often starts at the edge, although this last point is very sensitive to the boundary values.

The calculations shown in Fig. 7 have been repeated using effective ripple profiles like those published previously $[12,17,36]$ for the same TJ-II magnetic configuration (remember that the two magnetic configurations used here are practically equivalent). In particular, the $\varepsilon_{\text {eff }}$ profiles shown in references $[12,17]$ are very similar and give correspondingly similar results under the analytical model of Ref. [24] used in the present paper. We have taken a profile in between these two that can be expressed with a simple formula,

$$
\varepsilon_{\text {eff }}=0.054 \cdot 10^{\rho} \text {. }
$$

As mentioned before, the values given by this effective ripple profile are approximately one order of magnitude larger than those of the profile that approximates HIBP data (Eq. 4) and, consequently, overestimate the plasma potential because electron transport is promoted: $\varphi(0)$ at low densities is larger than the experimental values, and it reaches less negative values at high densities. On the other hand, this effective ripple yields numerical results that are comparable to DKES calculations with the same plasma profiles. This can be appreciated in Fig. 10, where we show the comparison between the plasma potential values (with $\varphi_{a}=0$ in all cases) obtained with DKES
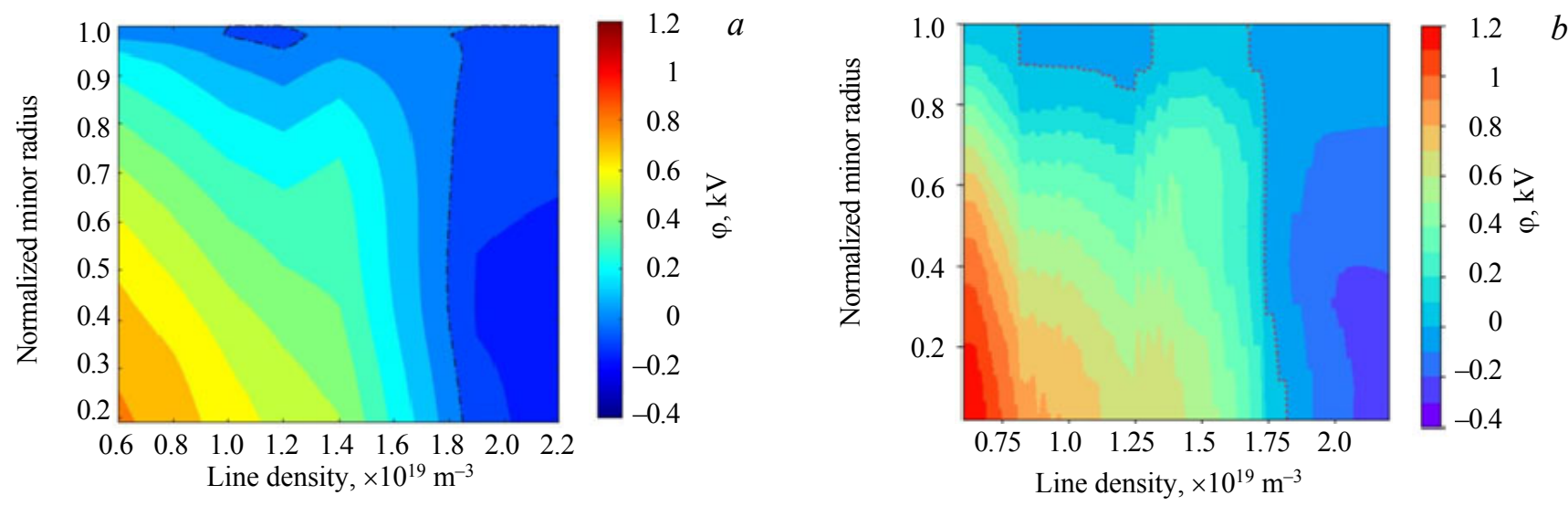

Fig. 10. Contour plots of the calculated plasma potential in density scans using $(a)$; DKES and the neoclassical model with $\varepsilon_{\mathrm{eff}}=0.054 \cdot 10^{\rho}(\mathrm{b})$

and the neoclassical model for the same given plasma profiles. In particular, we have taken the set of averaged discharges from configuration 100_44_64, to which we have added profiles from single discharges at densities 1.0, 1.2, 1.4, 1.9 and $2.2\left(\times 10^{19} \mathrm{~m}^{-3}\right)$ in order to extend the scan. DKES results are quite similar to the results found with the 
semi-analytical formulation. This is not surprising because a similar result was obtained previously [13] using the same model formulation and a not too different effective ripple (around a 70\% of the present one).

We ought to mention here that the calculations from DKES have also important uncertainties related to the lack of convergence of the monoenergetic diffusion coefficients $\left(D_{11}\right)$ at low collisionalities and large radial electric fields. In order to set the values in this regime we used a criterion based on the interpolation to the expected analytical collisionality scalings $(\sim 1 / v, \sim \sqrt{v}$ or $\sim v)$ which still leaves some uncertainty in the values. Also, sometimes there is a significant variation in $D_{11}$ from one flux surface to the next leading to «spiky» profiles for $E_{r}$ and the particle fluxes.
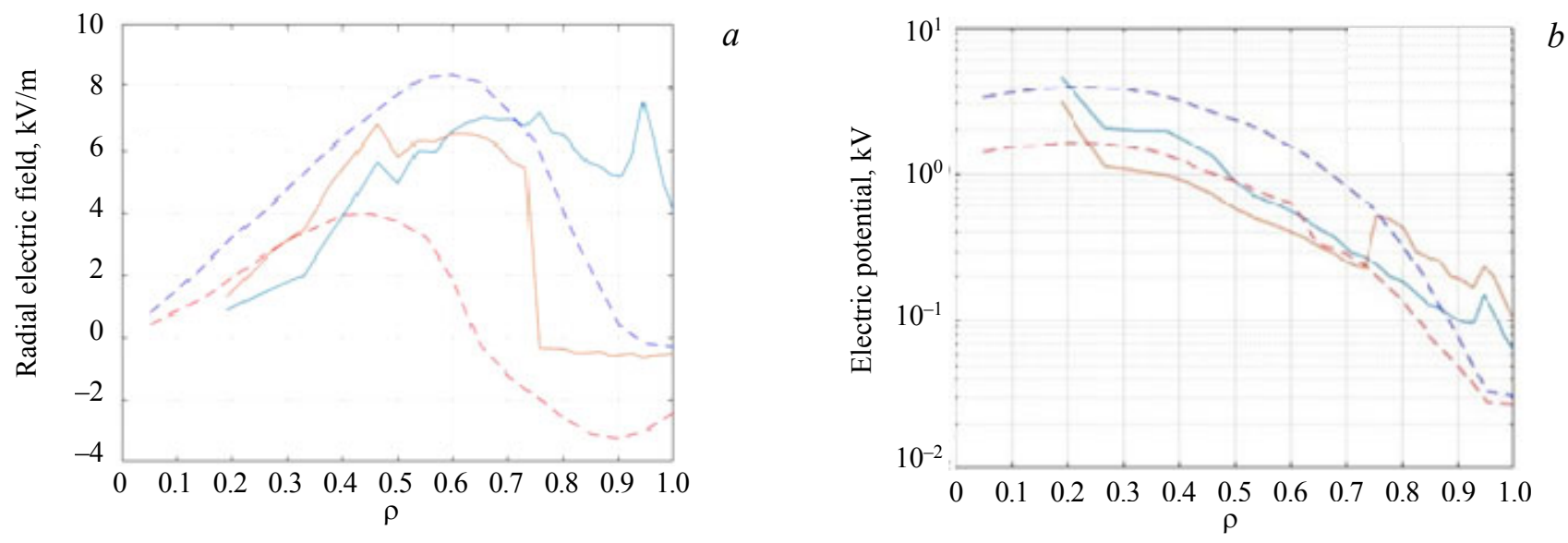

Fig. 11. Radial electric field from DKES calculations (lines) and from the analytical model (dashes) ( $a$ ); corresponding electron diffusivity. Plasma profiles correspond to the stage 1 (blue) and stage 2 (red) of the two-stage experiments (see Fig. 4) (b): - — DKES stage 1; — DKES stage 2 ; - - - - Beidler stage $1 ;---$ - Beidler stage 2

As a further comparison between the numerical calculations with DKES and the analytical model, in Fig. 11 we compare the profiles of radial electric field and neoclassical electron diffusivity in the two stage experiments.

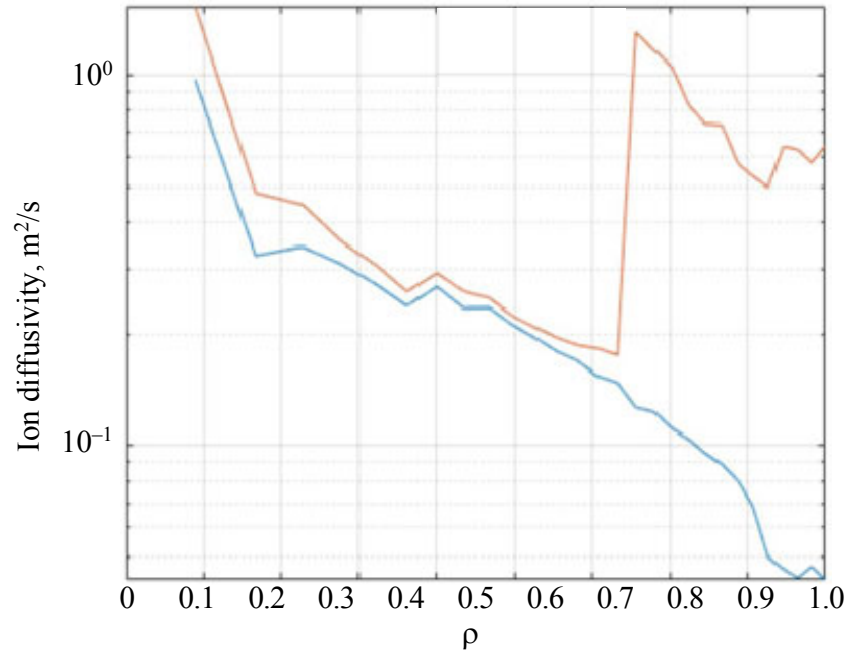

Fig. 12. Ion thermal diffusivity profiles from DKES calculations using the plasma profiles that correspond to stage 1 (blue) and stage 2 (red) of the two-stage experiments (see Fig. 4); — — DKES stage $1 ;$ - D DKES stage 2
In agreement with Fig. 10, the magnitudes of $E_{r}$ and $D_{e}$ are more or less the same for the analytical model and DKES estimates although the radial profiles are not exactly the same. At larger radii, DKES produces $E_{r}$ values that are more positive than the analytical model for both stages. On the other hand, the diffusivity has a better agreement near the edge region for the two calculations while the values in the plasma bulk from DKES tend to be lower than those from the analytical model of Ref. [24]. Our results from DKES for the diffusivities have the same trends found in previous works based on Monte Carlo simulations [17] and also on DKES computations [12], namely, the electron thermal diffusivity has an increment near the central plasma (see Fig. 11, $b$ while the ion thermal diffusivity, shown in Fig. 12, has an increment in a region closer to the edge, especially seen here for stage 2. The well-known poor convergence of DKES at low collisionalities is responsible for the large fluctuations in the radial profiles. We also point out that the inaccuracy of the experimental ion temperature produces large uncertainties in $E_{r}$ since it is quite sensitive to the relative values of the ion to electron temperatures, especially near the edge. The transition from the electron root (positive $E_{r}$ ) to the ion root (negative $E_{r}$ ) can change by modifying the edge $T_{i}$. At whole, the agreement between the two calculations can be reasonably good when the effective ripple is of the order of that used in the literature. 
We end the presentation of results showing the radial electric field obtained from the neoclassical model in an extended range of densities. Fig. 13 shows the pattern of variation $E_{r}\left(\rho, n_{e}\right)$ from the neoclassical estimate using the same color scale as in Fig. 9 to ease the comparison (white means out of range). The patterns in both figures are roughly similar except that the line-density values are not coincident (note the horizontal scales in Fig. 9 and 13). This fact moved us to play with the uncertain ion temperature up to twice the measured values, which has been found to be insufficient to explain the disagreement between measurements and model. We see that the trends and the order of magnitude of the $E_{r}$ values are comparable between NC calculations and experiments, but the differences

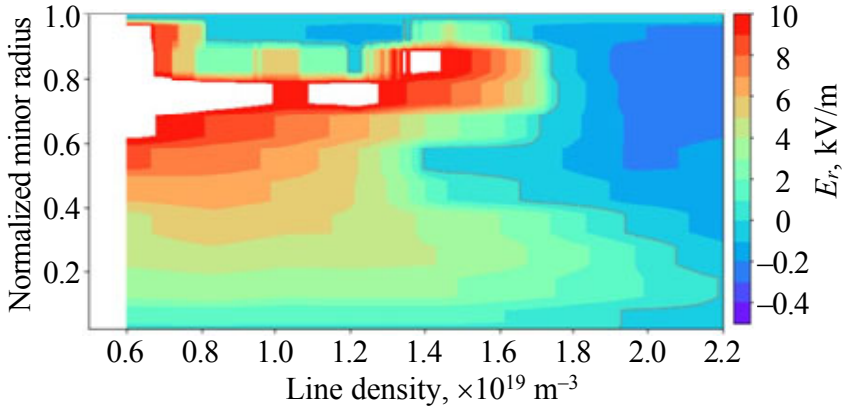

Fig. 13: Contour map of the neoclassical estimate of the radial electric field for the broad ECRH experiments extended to the beginning of the NBI phase (see Fig. 1). The inputs to the model are average profiles of similar density discharges (shown in subsection «Discharges...»). Zones in white are out of the range indicated in the color bar are significant enough to make a fine comparison and an assessment of the errors not worth it.

\section{DISCUSSION AND CONCLUSIONS}

In this work, we have used experimental data from ECRH plasmas of the TJ-II heliac to make two comparisons: (i) experimental data versus neoclassical calculations and (ii) numerical kinetic calculations versus analytical formulae. Two sets of discharges were used, for which plasma profiles and the corresponding HIBP measurements of the electric potential are available and validated.

The analytical calculation captures the qualitative behavior of both, the experimental data (Figs. 5 and 7) and the numerical values obtained with the kinetic code DKES (Fig. 10). This means that neoclassical scalings and dependencies can explain to a good extent the radial electric field in TJ-II plasmas. The comparison between kinetic calculations (where the effective ripple is an output) and the analytical formulation using the same effective ripple indicates that the formulation reproduces quite well the dependencies and values of the neoclassical fluxes obtained numerically; and, consequently, the radial electric fields. With respect to the comparison with the experimental values of the plasma potential, we have found that quantitative agreement between the neoclassical formulation and the experimental data can be found to an acceptable level by adjusting the effective ripple, but the needed value is an order of magnitude smaller than the one used in DKES comparisons. Therefore, referring now to DKES or analytical calculations as, simply, neoclassical model, a main result of this study is that the quantitative differences between experiments and model are too large for an acceptable assessment of the latter with the assumed hypothesis (local fluxes, gyro-center approximation etc.). We have played with the most uncertain of our inputs, namely the ion temperature, in order to find out at what extent a systematic modification of the $T_{i}$ profiles could make the neoclassical model approach the experimental values. As far as we have checked, quite high $T_{i}$ profiles, around twice the typical measurements, are still not enough to «force» a similarity of theoretical and experimental data for the plasma potential in the scans here studied. It is acknowledged, at this respect, that the boundary and near-boundary values of all the main plasma profiles, especially the electron and ion temperatures, can give rise to large differences in the core plasma potential due to its integral nature, but the comparison of the experimental and estimated electric fields clearly indicates that a change of the edge temperature values is not enough either to explain the discrepancies.

If we reject $T_{i}$ as the main source of discrepancy, it is in order mentioning other possibilities here. Supra thermal electrons related with ECRH in the TJ-II stellarator have been indeed identified [38], and their presence would increment the radial electron fluxes [39] which would tend to shift the electric field values to the positive side (electron root). For the present experiments, we reject this as a cause for discrepancy because supra thermal electrons would then take the neoclassical results further from the experiment and, additionally, we have chosen discharges where this effect is expected to be mitigated in most of the studied plasmas. More important might be the non-local effects on the particle fluxes, which have been found to be considerable in a large magnetic ripple machine as TJ-II is. In a previous study [40] the ion fluxes were found larger than those obtained using the local 
ansatz (as is the case of DKES and the model calculations in the present work), which would tend to decrease the plasma potential in the estimates of collisional transport. In favor of this possibility we can argue that the TJ-II magnetic configurations used correspond to large magnetic ripple simply because they are large and, consequently, the plasma gets closer to the magnetic field coils; and also that the electrons are expected to have smaller drifts (aside from $\mathbf{E} \times \mathbf{B}$ ) than the ions so the nonlocal effects are expected to be less pronounced in them. In consequence, nonlocal effects in TJ-II are expected to increase the ion fluxes more than the electron fluxes promoting in this way a shift of the radial electric fields towards negative values, possibly improving the agreement with the measurements. Other effects can also affect the resulting electric fields, like the effective charge or the variations of the electric potential on a flux magnetic surface [41], but these effects would require dedicated studies before making any conjecture.

It is worth mentioning here that most ECRH TJ-II plasmas operate below line density $0.7 \cdot 10^{19} \mathrm{~m}^{-3}$ and under ECRH power above $400 \mathrm{~kW}$. In these cases, the radial electric field is positive in the central region, as seen in Figs. 8 and 11. This means that the concept of core electron root confinement (CERC) observed in some stellarators, which involves a transition from the ion to the electron root, should not be invoked for the TJ-II case as done in [15], because the phenomenon in the TJ-II case happens in plasma conditions, where the radial electric field must be positive in most or all of the plasma. Rather, the physics for the apparent enhancement of the electron heat confinement observed in TJ-II ECRH discharges includes two ingredients related with the radial electric field: (i) the neoclassical electric field in the core plasma, where the phenomenon occurs, is already in the electron root prior to the change in electron temperature profiles [14]; and (ii) the presence of a low-order rational number of the rotational transform near the ECRH deposition zone helps, if it is not necessary as it seems, to provoke the transition [42]. Many later experiments support these notions (see [43] and references therein). The CERC or CERC-like discharges were intensively explored in TJ-II with HIBP measurements of plasma potential. The initial data indicates the effect in the core plasma potential, accompanying the increase of the central electron temperature [4446]. The detailed analysis of CERC plasma potential profiles presents the targeted future studies.

The present study explored the density variation, that is allowed in ECRH plasmas. This is relatively lowdensity case. The higher-density (high-collisionality) NBI plasmas also present an important issue for NC approach $[4,13]$. The similar studies were done for higher density plasmas in tokamaks $[5,6]$. However, the situation in such plasmas is in some sense simpler since the ion transport is dominated over electron one and $E_{\mathrm{r}}$ is not implicitly included in the transport coefficients. The observed negative electric field, resembling the one in higher density stellarator plasmas, was analyzed even for the 3D realistic case of the tokamak with toroidal ripple $[47,48]$. For stellarators this topic deserves a separate study and it is planned for the future.

In conclusion, we have done a study based on measurements of plasma potential profiles in repetitive plasmas of the TJ-II stellarator with several densities on the order of $10^{19} \mathrm{~m}^{-3}$ under ECRH. We have found that:

- local neoclassical calculations of the electron and ion fluxes using the numerical code DKES and model formulae for the mono-energetic transport coefficients are found in fair agreement when the effective ripple obtained from the numerical calculations are used in the formulation (see Fig. 10). We call this «neoclassical estimates»;

- using the neoclassical formulation we can mimic acceptably the experimental plasma-potential profiles at the expense of reducing the effective ripple and increasing the ion temperature with respect to the values obtained from the CX-NPA diagnostic (compare Figs. 5 and 7). With the standard effective ripple, the neoclassical estimates of the plasma potential are considerably larger than the experimental values;

- the comparison of the radial electric fields between neoclassical estimates and measurements (Figs. 8 and 9 for HIBP data, and 13 for the calculations) is good within order of magnitude, but there are notable differences in the profiles for each line-density value in this study;

- the so called CERC phenomenon must be considered in TJ-II plasmas, as a phenomenon that happens in already electron-root plasmas. Therefore, the explanation must go beyond the mere passage from electron to ion-root conditions.

The research was funded by Russian Science Foundation, Project 19-12-00312, AVM was partly supported by the Competitiveness Program of NRNU MEPhI. Support from IAEA CRP F13019 «Network of Small and Medium Size Magnetic Confinement Fusion Devices for Fusion Research», Contract A1-S-24157 and PAPIITUNAM IN112118 projects is also acknowledged. 


\section{REFERENCES}

1. Vargas V.I., Lopez-Bruna D., Herranz J., Castejon F. and the TJ- II Team. - Nucl. Fusion, 2007, vol. 47, p. 1367.

2. Tallents S., Lopez-Bruna D., Velasco J.L., Ochando M.A., van Milligen B.P., Vargas V.I., Martinell J.J., Tafalla D., Fontdecaba J.M., Herranz J., Blanco E., Tabares F.L., Estrada T., Pastor I. and the TJ-II Team. Plasma Phys. Control. Fusion, 2014, vol. 56, 075024.

3. Yamada H., Harris J., Dinklage A., Ascasibar E., Sano F., Okamura S., Talmadge J., Stroth U., Kus A., Murakami S., Yokoyama M., Beidler C., Tribaldos V., Watanabe K., Suzuki Y. — Nucl. Fusion, 2005, vol. 45, p. 1684.

4. Melnikov A.V., Dyabilin K.S., Eliseev L.G., Lysenko S.E., Dnestrovskij Yu.N. Measurement and modelling of electric potential in the TJ-II stellarator. - VANT. Ser. Termoyadernyi sintez (Problems of Atomic Science and Technology. Ser. Thermonuclear Fusion), 2011, issue 3, p. 54-73 (in Russian).

5. Melnikov A., Hidalgo C., Eliseev L., Ascasibar E., Chmyga A., Dyabilin K., Krasilnikov I., Krupin V., Krupnik L., Khrebtov S., Komarov A., Kozachek A., Lopez-Bruna D., Lysenko S., Mavrin V., de Pablos J., Pastor I., Perfilov S., Pedrosa M., Shurygin R., Vershkov V. — Nucl. Fusion, 2011, vol. 51, 083043.

6. Melnikov A., Hidalgo C., Ido T., Shimizu A., Fujisawa A., Dyabilin K., Lysenko S. — Plasma Fusion Research, 2012, vol. 7, 2402114.

7. Melnikov A.V. Electric Potential in Toroidal Plasmas (Springer Nature, Switzerland, AG, 2019) ISBN 978-3-03003480-1.

8. Krupnik L., Alonso A., Ascasibar E., Estrada T., Hidalgo C., van Milligen B., Ochando M., Pedrosa M., de Pablos J.L., Tribaldos V., Chmyga A., Dreval N., Deshko G., Khrebtov S., Komarov A., Kozachok A., Tereshin V., Eliseev L., Melnikov A., Silva C. - Czech. J. Phys., 2005, vol. 55, p. 317-339.

9. Melnikov A., Eliseev L., Grashin S., Gudozhnik A., Lysenko S., Marvin V., Perfilov S., Vershkov V., Krupnik L., Chmyga A., Komarov A., Kozachok A., Hidalgo C., Alonso A., de Pablos J., Pedrosa M. — Czech. J. Phys, 2005, vol. 55, p. 1569 .

10. Tribaldos V. - Phys. Plasmas, 2001, vol. 8, p. 1229.

11. Garcia J., Dies J., Castejon F., Yamazaki K. — Phys. Plasmas, 2007, vol. 14, 102511.

12. Velasco J.L., Castejon F. — Plasma Phys. Control. Fusion, 2012, vol. 54, 015005.

13. Gutierrez-Tapia C., Martinell J.J., Lopez-Bruna D., Melnikov A.V., Eliseev L., Rodriguez C., Ochando M.A., Castejon F., Garcia J., van Milligen B.P., Fontdecaba J.M. — Plasma Phys. Control. Fusion, 2015, vol. 57, 115004.

14. Castejon F., Tribaldos V., Garcia-Cortes I., de la Luna E., Herranz J., Pastor I., Estrada T. and TJ-II Team. Nucl. Fusion, 2002, vol. 42, p. 271.

15. Yokoyama M., Maßßberg H., Beidler C., Tribaldos V., Ida K., Estrada T., Castejon F., Fujisawa A., Minami T., Shimozuma T., Takeiri Y., Dinklage A., Murakami S. Yamada H. - Nucl. Fusion, 2007, vol. 47, p. 1213.

16. Beidler C., Allmaier K., Isaev M., Kasilov S., Kernbichler W., Leitold G., Maaßberg H., Mikkelsen D., Murakami S., Schmidt M., Spong D., Tribaldos V., Wakasa A. - Nucl. Fusion, 2011, vol. 51, 076001.

17. Turkin Y., Beidler C.D., Maaßberg H., Murakami S., Tribaldos V., Wakasa A. — Phys. Plasmas, 2011, vol. 18, 022505.

18. Dinklage A., Yokoyama M., Tanaka K., Velasco J., Lopez-Bruna D., Beidler C., Satake S., Ascasibar E., Arevalo J., Baldzuhn J., Feng Y., Gates D., Geiger J., Ida K., Isaev M., Jakubowski M., Lopez-Fraguas A., Maaßberg H., Miyazawa J., Morisaki T., Murakami S., Pablant N., Kobayashi S., Seki R., Suzuki C., Suzuki Y., Turkin Y., Wakasa A., Wolf R., Yamada H., Yoshinuma M., LHD Group, TJ-II Team and W7-AS Team. Nucl. Fusion, 2013, vol. 53, 063022.

19. Lopez-Bruna D., Velasco J.L., Ochando M., Guasp J., Lopez-Fraguas A., van Milligen B.P., Ascasibar E., Liniers M., Estrada T., Fontdecaba J.M., Pastor I., Tafalla D., Medina F., Eliseev L., Melnikov A., Perfilov S., Herranz J., Zurro B., McCarthy K.J., Tabares F. and the TJ-II Team. - Plasma Phys. Control. Fusion, 2013, vol. 55, 015001 .

20. Velasco J.L., McCarthy K.J., Panadero N., Satake S., Lopez-Bruna D., Alonso A., Calvo I., Dinklage A., Estrada T., Fontdecaba J.M., Hernandez J., Garcia R., Medina F., Ochando M., Pastor I., Perfilov S., Sanchez E., Soleto A., van Milligen B.P., Zhezhera A. and the TJ-II Team. - Plasma Phys. Control. Fusion, 2016, vol. 58, 084004

21. Zurro B., Baciero A., Rapisarda D., Tribaldos V. and TJ-II team. — Fusion Sci. Technol., 2006, vol. 50, p. 419427.

22. Lopez-Bruna D., Reynolds J.M., Cappa A., Martinell J., Garcia J., Gutierrez-Tapia C. Programas perifericos de ASTRA para el TJ-II, 2010, Informes Tecnicos Ciemat № 1201, CIEMAT, URLhttp://documenta.ciemat.es/bitstream/123456789/114/1/40921_IC1201.pdf.

23. Gutierrez-Tapia C., Martinell J.J., Lopez-Bruna D., Melnikov A.V. — J. Phys.: Conf. Series, 2015, vol. 591, 
012011.

24. Beidler C.D. Neoclassical Transport Properties of HSR. Report 2/331, 1996, IPP-Garching.

25. Hirshman S.P., Shaing K.C., van Rij W.I., Beasly C.O. Jr., Crume E.C. — Phys. Fluids, 1986, vol. 29 , p. 2951.

26. Van Milligen B.P., Estrada T., Ascasibar E., Tafalla D., Lopez-Bruna D., Fraguas A.L., Jimenez J.A., GarciaCortes I., Dinklage A., Fischer R. - Rev. Sci. Instrum., 2011, vol. 82, 073503.

27. Fontdecaba J.M., Pastor I., Arevalo J., Herranz J., McCarthy K.J., Sanchez-Burillo G. — Plasma Fusion Res., 2010, vol. 5, S2085.

28. Guzman F., Tabares F.L., Tafalla D., Garcia-Cortes I., Balbin R. - J. Nucl. Mater., 2009, vol. 390-391, p. $1127-1130$.

29. Pelaez R.J., Zurro B., Baciero A., Rapisarda D., Clark C.J. — Phys. B: Atomic, Molecular and Optical Physics, 2010, vol. 43, 144016.

30. Melnikov A., Krupnik L., Eliseev L., Barcala J., Bravo A., Chmyga A., Deshko G., Drabinskij M., Hidalgo C., Khabanov P., Khrebtov S., Kharchev N., Komarov A., Kozachek A., Lopez J., Lysenko S., Martin G., Molinero A., de Pablos J., Soleto A., Ufimtsev M., Zenin V., Zhezhera A. - Nucl. Fusion, 2017, vol. 57, 072004.

31. Sharma R., Khabanov P., Melnikov A., Hidalgo C., Cappa A., Chmyga A., Eliseev L.G., Estrada T., Kharchev N.K., Kozachek A.S., Krupnik L.I., Malaquias A., van Milligen B., Molinero A., de Pablos J.L., Pastor I., Zenin V.N. - Phys. Plasmas, 2020, vol. 27, 062502.

32. Maaßberg H., Beidler C.D., Simmet E.E. — Plasma Phys. Control. Fusion, 1999, vol. 41, p. 1135.

33. Pereverzev G.V., Yushmanov P.N. ASTRA Automated System for TRansport Analysis. Tech. Rep. IPP 5/98, Max Plank Institut für Plasmaphysik, Garching, 2002.

34. Reiter D. The EIRENE code user manual (including: B2-EIRENE interface), 2005; URL http://www.eirene.de/html/manual.html.

35. Vargas V.I., Lopez-Bruna D., Guasp J., Herranz J., Estrada T., Medina F., Ochando M., Velasco J.L., Reynolds J.M., Ferreira J.A., Tafalla D., Castejon F., Salas A. Density dependence of particle transport in ECH plasmas of the TJ-II stellarator. Tech. Rep. № 1162. Ciemat, Madrid, Spain, 2009.

36. Seiwald B., Kasilov S., Kernbichler W., Kalyuzhnyj V., Nemov V., Tribaldos V., Jimenez J. — J. Comput. Phys., 2008, vol. 227, p. 6165-6183.

37. Happel T., Estrada T., Hidalgo C. - Europhys. Lett., 2008, vol. 84, p. 65001.

38. Ochando M.A., Medina F. and the TJ-II Team. - Plasma Phys. Control. Fusion, 2003, vol. 45, p. 221.

39. Martinell J.J. — Radiat. Eff. Defect. S., 2016, vol. 171, p. 103-108.

40. Tribaldos V., Guasp J. - Plasma Phys. Control. Fusion, 2005, vol. 47, p. 545-559.

41. Calvo I., Parra F.I., Velasco J.L., Alonso J.A. — Plasma Phys. Control. Fusion, 2017, vol. 59, 055014.

42. Castejon F., Lopez-Bruna D., Estrada T., Ascasibar E., Zurro B., Baciero A. - Nucl. Fusion, 2004, vol. 44 , p. 593.

43. Estrada T., Medina F., Lopez-Bruna D., Ascasibar E., Balbin R., Cappa A., Castejon F., Eguilior S., Fernandez A., Guasp J., Hidalgo C., Petrov S. - Nucl. Fusion, 2007, vol. 47, p. 305.

44. Estrada T., Krupnik L., Dreval N., Melnikov A.V., Khrebtov S.M., Hidalgo C., van Milligen B., Castejón F., Ascasíbar E., Eliseev L., Chmyga A.A., Komarov A.D., Kozachok A.S., Tereshin V. — Plasma Phys. Control. Fusion, 2004, vol 46, № 1, p. 277-286.

45. Estrada T., Alonso A., Chmyga A.A., Dreval N., Eliseev L., Hidalgo C., Komarov A.D., Kozachok A.S., Krupnik L., Melnikov A.V., Nedzelskiy I.S., de Pablos J.L., Pereira L.A., Tashev Yu., Tereshin V., Vargas I. Plasma Phys. Control. Fusion, 2005, vol. 47, № 11, p. L57-L63.

46. Estrada T., López-Bruna D., Alonso A., Ascasíbar E., Baciero A., Cappa A., Castejón F., Fernández A., Herranz J., Hidalgo C., de Pablos J.L., Pastor I., Sánchez E., Sánchez J., Krupnik L., Chmyga A., Dreval N., Khrebtov S.M., Komarov A.D., Kozachok A.S., Tereshin V., Melnikov A.V., Eliseev L. — Fusion Science and Technology, 2006, vol. 50, № 2, p. 127-135.

47. Isaev M.Yu., Beidler C.D., Chudnovskiy A.N., Dyabilin K.S., Maassberg H., Melnikov A.V., Perfilov S.V., Turkin Y. - In: Proc. 39th EPS Conference \& 16th Intern. Congress on Plasma Physics. Stockholm, Sweden (2-6 July 2012), ECA, vol. 36A, Rep. P2.077; http://ocs.ciemat.es/epsicpp2012pap/html/.

48. Melnikov A.V., Eliseev L.G., Perfilov S.V., Andreev V.F., Grashin S.A., Dyabilin K.S., Isaev M.Yu., Chudnovskiy A.N., Lysenko S.E., Mavrin V.A., Mikhailov M.I., Ryzhakov D.V., Shurygin R.V., Zenin V.N. and the T10 Team. - Nucl. Fusion, 2013, vol. 53, p. 093019.

\section{AUTHORS}

Lopez-Bruna D. Laboratorio Nacional de Fusion, CIEMAT, 28040-Madrid, Spain

Gutierrez-Tapia C. Instituto Nacional de Investigaciones Nucleares, 52045 Ocoyoacac, Edo. de Mexico, Mexico 
Martinell J.J. Instituto de Ciencias Nucleares, Universidad Nacional Autonoma Mexico, Mexico D.F., Mexico

Melnikov A.V. NRC “Kurchatov Institute”, pl. Akademika Kurchatova 1, 123182 Moscow, Russia; Melnikov_AV@nrcki.ru

Eliseev L.G. NRC “Kurchatov Institute”, pl. Akademika Kurchatova 1, 123182 Moscow, Russia; Eliseev_LG@nrcki.ru

Khabanov Ph.O. NRC “Kurchatov Institute”, pl. Akademika Kurchatova 1, 123182 Moscow, Russia; Khabanov_PO@nrcki.ru

Pastor I. Laboratorio Nacional de Fusion, CIEMAT, 28040-Madrid, Spain

Tafalla D. Laboratorio Nacional de Fusion, CIEMAT, 28040-Madrid, Spain 